\title{
Switching between Dialysis Modality: A Descriptive Study in Provence-Alpes-Côte D'azur
}

\author{
Aida Habib ${ }^{1}$ (D), Anne-Claire Durand ${ }^{1}$, Roland Sambuc ${ }^{2}$,Franck Mazue ${ }^{2}$ and Stéphanie Gentile \\ ${ }^{1}$ Al-Andalus University for Medical Sciences, Faculty of Hospital Management, Qadmus, Syria \\ ${ }^{2}$ Laboratoire de Santé Publique, Faculté de Médecine, 27 Bouvard Jean Moulin, France
}

\begin{abstract}
To our knowledge, few studies in France have so far investigated the difference in patient characteristics and outcome between patients switching from hemodialysis (HD) to peritoneal dialysis (PD) and from DP to HD during treatment period. Therefore, the aim of the present retrospective study was to analyze main characteristics and outcome of switching patients and to identify risk factors that influence the outcome of switching patients.

In this cohort study, we included all patients from the French Renal Epidemiology and Information Network who initiated dialysis between 2004 and 2012, and followed up to June 30 ${ }^{\text {th }}$ 2014, in one French region (Provence-Alpes-Côte d'Azur). Characteristics of patient and outcome were analyzed.

During the study period, 136 PD patients switched to HD and $60 \mathrm{HD}$ patients switched to PD, for a total of 196 patients. Patients who switched from HD to PD were younger and most of them started dialysis in emergency, compared to those switching from PD to HD. Mortality rate was significantly lower for switching patients compared to non-switching patients $(p=0.004)$, but there was not a significant difference between patients switching from PD and those switching from HD. Switching to HD improve significantly the survival for DP patients. Switching to DP improve the survival for $\mathrm{HD}$ patients but not significantly. In conclusion, switching to HD improve positively the survival compared to those who remained on $\mathrm{PD}$, whereas, switching to $\mathrm{PD}$ is not significant.
\end{abstract}

Keywords

Hemodialysis, Peritoneal dialysis, Switching, Dialysis modality, Chronic renal failure, Survival, Mortality, Outcome

\section{Introduction}

Three methods can be used to treat chronic renal failure: Hemodialysis (HD), peritoneal dialysis (PD) and renal transplantation. HD and PD are the two major modalities of dialysis. These modalities differ clinically; both offering advantages and disadvantages for an individual patient $[1,2]$. The choice between these two modalities is influenced by medical and non-medical factors such as social characteristics, logistic considerations [3-12]. One single modality may not procure adequate treatment over an entire lifespan. Therefore, nephrologists sometimes have to recommend switching modalities during the clinical course of ESRD patients [13]. In France, on December $31^{\text {st }} 2013,93.3 \%$ of patients were treated with hemodialysis, while peritoneal dialysis was used in just $6.7 \%$ of dialysis patients [14]. On a long term period on PD, the number of peritoneal dialyses is low due to various reasons such as episodes of peritonitis, membrane failure or patients fatigue, etc... $[15,16]$. Indeed, some nephrologists recommend to switch patients from PD to HD after 2 or 3 years, even with goof aspect of treatment [13].

Many studies have compared HD versus PD as first treat- ment of renal function substitution therapy RFST [17-29]. In contrast a little number of studies [30-37] analyzed the profile and the outcome of patients switching from PD to HD or vice versa, due to the limited number of available data. In France, to our knowledge, there are few $[38,39]$ data able to describe and compare the characteristics and the outcome of the patients. No study has been performed in the French region of Provence-Alpes-Côte d'Azur (PACA).

The aim of the study was to analyze main characteristics and outcome of switching patients and to identify risk factors that influence the outcome.

*Corresponding author: Aida HABIB, Al-Andalus University For Medical Sciences, Faculty Of Hospital Management, Qadmus, Syria

Accepted: May 18, 2020

Published online: May 20, 2020

Citation: Habib A, Anne-Claire D, Sambuc R, et al. (2020) Switching between Dialysis Modality: A Descriptive Study in ProvenceAlpes-Côte D'azur. Ann Nephrol 5(1):60-70 
Citation: Habib A, Anne-Claire D, Sambuc R, et al. (2020) Switching between Dialysis Modality: A Descriptive Study in Provence-Alpes-Côte D'azur. Ann Nephrol 5(1):60-70

\section{Results}

During the study period (from 2004 to 2014), among a total of 7,203 patients who had begun a dialysis treatment, 6,976 didn't have any switch, 196 patients had one switch and 31 patients had two or more switches. These last 31 patients were excluded from our analysis. So, a total of 7,172 patients were included in our analysis: 6,724 patients (93.75\%) began on HD and 448 (6.25\%) on PD.

Among the 6,724 patients treated with hemodialysis, 60 patents $(0.89 \%)$ switched to PD whereas among the 448 treated with peritoneal dialysis, 136 patients $(30.35 \%)$ switched to HD during the study period.

\section{Baseline characteristics}

At the start of dialysis, mean age of patients with a modality switch was $65.13 \pm 16.75$ years. Mean age at time of switch was $66.93 \pm 16.8$ yrs: $62.5 \pm 15.9$ years for patients switching from HD to PD and $68 \pm 16$ years for patients switching from PD to $H D, p=0.016$.

Hypertension and diabetes diseases were the two main causes of renal disease among the patients switching $39.1 \%$ and $24.5 \%$ respectively. The main co-morbidities of the patients were cardiovascular disease (43.8\%) and diabetes disease (34.9\%). The major risk factor was hypertension (78.3\%).

Table 1 shows the distribution of characteristics of the

Table 1: Distribution of characteristics of patients.

\begin{tabular}{|c|c|c|c|c|c|c|c|c|c|}
\hline & Switch & & & & Non switch & & & $\begin{array}{l}\text { PD vs. } \\
\text { PD-HD }\end{array}$ & $\begin{array}{l}\text { HD vs. } \\
\text { HD-PD }\end{array}$ \\
\hline Characteristics & Total & HD to DP & DP to HD & P Value & HD & DP & P Value & P Value & P Value \\
\hline Total, n & 196 & 60 & 136 & & 6664 & 312 & & & \\
\hline Sex, n(\%): Men & 121 (61.7) & $39(65)$ & $82(60.3)$ & 0.633 & 4295 (64.5) & 190 (60.9) & 0.205 & 0.904 & 0.928 \\
\hline Age: (Year) & $65.1 \pm 16.7$ & $61.6 \pm 16.2$ & $66.6 \pm 16$ & 0.056 & $69.99 \pm 14.43$ & $68.5 \pm 17.7$ & 0.153 & 0.295 & 0 \\
\hline Min-Max & & {$[22.3 \pm 92.1]$} & [19.7-8] & & [18.1-97.3] & \multicolumn{2}{|l|}{ [18.3-95.5] } & & \\
\hline \multicolumn{2}{|l|}{ Age category n (\%) } & & & 0.024 & $469(7)$ & $40(12.8)$ & 0 & 0.386 & 0 \\
\hline$\leq 45$ & $25(12.8)$ & $10(16.7)$ & $15(11)$ & & & & & & \\
\hline $46-65$ & $61(31.1)$ & $26(43.3)$ & $35(25.7)$ & & $1557(23.4)$ & 71 (22.9) & & & \\
\hline $66-75$ & $41(20.9)$ & $10(16.7)$ & $31(22.8)$ & & 1659 (24.9) & $54(17.3)$ & & & \\
\hline$>75$ & $69(35.2)$ & $14(23.3)$ & $55(40.4)$ & & $2980(44.7)$ & $147(47.1)$ & & & \\
\hline \multicolumn{3}{|c|}{ Primary renal disease $\mathrm{n}(\%)$} & & 0.335 & & & 0.099 & 0.297 & 0.081 \\
\hline Diabetes & $48(24.5)$ & $12(20)$ & $36(26.5)$ & & $1416(21.2)$ & $56(17.9)$ & & & \\
\hline Glomerulonephritis & $24(12.2)$ & $11(18)$ & $13(9.6)$ & & $604(9.1)$ & 37 (11.9) & & & \\
\hline Hypertension & $59(30.1)$ & $20(33.3)$ & $39(28.7)$ & & $1944(29.2)$ & $106(34)$ & & & \\
\hline vascular & $1(0.5)$ & 0 & 1 & & $63(0.9)$ & $2(0.6)$ & & & \\
\hline Other disease & $64(32.7)$ & $17(28.3)$ & $47(34.6)$ & & 2638 (39.6) & $111(35.6)$ & & & \\
\hline $\begin{array}{l}\text { EPO before } \\
\text { dialyse: Yes } n(\%)\end{array}$ & $83(42.3)$ & $13(21.7)$ & $70(51.5)$ & 0 & $2204(41.1)$ & $170(54.5)$ & 0 & 0.123 & 0.031 \\
\hline Creatinin initial & $618.6 \pm 248.6$ & $682.5 \pm 295$ & $589.2 \pm 219.1$ & 0.057 & $600.9 \pm 271.9$ & $561.8 \pm 237.5$ & 0.015 & 0.319 & 0.041 \\
\hline Albumin initial & $35.1 \pm 6.91$ & $35 \pm 9.59$ & $35.5 \pm 5.5$ & 0.995 & $32.6 \pm 6.5$ & $36.6 \pm 7.5$ & 0.618 & 0.16 & 0.083 \\
\hline Haemoglobin initial & $10.6 \pm 1.5$ & $10.2 \pm 1.8$ & $10.9 \pm 1.4$ & 0.015 & $10.2 \pm 1.6$ & $10.7 \pm 1.5$ & 0 & 0.313 & 0.99 \\
\hline Urgent yes $\mathrm{n}(\%)$ & $38(22.8)$ & $25(51)$ & $13(11)$ & 0 & 1741 (26.1) & $13(4.2)$ & 0 & 0.048 & 0.002 \\
\hline $\mathrm{BMI} \mathrm{kg} / \mathrm{m}^{2}$ & $24.6 \pm 4.8$ & $23.5 \pm 4.9$ & $25.7 \pm 4.7]$ & 0.018 & $25.2 \pm 5.1$ & $24.7 \pm 4.1$ & 0.067 & 0.305 & 0.007 \\
\hline Albumin & $34.2 \pm 8.6$ & $33.9 \pm 8.6$ & $34.38 \pm 5.2$ & 0.715 & $33.5 \pm 6.4$ & $34.6 \pm 6.9$ & 0.035 & 0.798 & 0.729 \\
\hline Haemoglobin & $10.7 \pm 1.6$ & $9.7 \pm 1.2$ & $11.27 \pm 1.66$ & 0 & $10.3 \pm 5.1$ & $11.2 \pm 1.4$ & 0 & 0.923 & 0.004 \\
\hline $\begin{array}{l}\text { EPO after start } \\
\text { dialyse: Yes } n(\%)\end{array}$ & $130(66.3)$ & 47 & 83 & 0.011 & 4819 (76.3) & 207 (66.3) & 0.057 & 0.412 & 0.112 \\
\hline Diabetes n (\%) & 67 (34.9) & $21(35)$ & $46(34.8)$ & 0.984 & 2374 (38.5) & $91(31)$ & 0.01 & 0.434 & 0.595 \\
\hline HTA n (\%) & $148(75.5)$ & $43(71.7)$ & $105(77.2)$ & 0.444 & $4729(78)$ & $230(80.1)$ & 0.422 & 0.997 & 0.523 \\
\hline $\begin{array}{l}\text { Cardiovascular } \\
\text { disease } \mathrm{n}(\%)\end{array}$ & 84 (42.9) & $30(50)$ & 54 (39.7) & 0.273 & 3355 (54.8) & $157(54.5)$ & 0.952 & 0.012 & 0.515 \\
\hline
\end{tabular}


Citation: Habib A, Anne-Claire D, Sambuc R, et al. (2020) Switching between Dialysis Modality: A Descriptive Study in Provence-Alpes-Côte D'azur. Ann Nephrol 5(1):60-70

\begin{tabular}{|c|c|c|c|c|c|c|c|c|c|}
\hline $\begin{array}{l}\text { Chronic respiratory } \\
\text { disease } \mathrm{n}(\%)\end{array}$ & $17(8.7)$ & $5(8.3)$ & $12(8.8)$ & 0.852 & 730 (12) & $25(8.7)$ & 0.093 & 0.873 & 0.434 \\
\hline \multicolumn{3}{|c|}{ Number co-morbidity n (\%) } & & 0.684 & & & 0.02 & 0.254 & 0.331 \\
\hline 0 & $70(36.5)$ & $19(31.7)$ & $51(38.6)$ & & $1521(24.6)$ & $94(31.8)$ & & & \\
\hline 1 & $58(30.2)$ & $19(31.7)$ & $39(29.5)$ & & $1860(30.1)$ & $79(26.7)$ & & & \\
\hline$\geq 2$ & $64(33.3)$ & $22(36.7)$ & $42(31.8)$ & & $2806(45.4)$ & $123(41.6)$ & & & \\
\hline Mobility n (\%) & & & & 0.158 & & & 0 & 0.311 & 0.369 \\
\hline Walk without help & $150(87.7)$ & $42(84)$ & \multicolumn{2}{|l|}{$108(89.3)$} & $3723(77.3)$ & $213(83.5)$ & & & \\
\hline $\begin{array}{l}\text { Totally dependent } \\
\text { for transfers }\end{array}$ & $6(3.5)$ & $4(8)$ & $2(1.7)$ & & $358(7.4)$ & $10(3.9)$ & & & \\
\hline $\begin{array}{l}\text { Need assistance for } \\
\text { transfers }\end{array}$ & $15(8.8)$ & $4(8)$ & $11(9.1)$ & & $737(15.3)$ & $32(12.5)$ & & & \\
\hline $\begin{array}{l}\text { Activity } \\
\text { professional Yes } \\
\text { n (\%) }\end{array}$ & $35(23)$ & $18(39.1)$ & $17(16)$ & 0.003 & $438(10.7)$ & $37(16.3)$ & 0.012 & 0.952 & 0 \\
\hline $\begin{array}{l}\text { Hospitalization yes: } \\
\text { n (\%) }\end{array}$ & 98 (64.1) & 29 (65.9) & $69(63.3)$ & 0.853 & $2366(49.2)$ & $146(65.8)$ & 0 & 0.713 & 0.033 \\
\hline Handicap yes & $17(9.2)$ & $7(12.7)$ & $10(7.7)$ & 0.403 & 797 (13.1) & 33 (11.6) & 0.474 & 0.233 & 0.968 \\
\hline
\end{tabular}

Table 2: Age at switching and time to first switch.

\begin{tabular}{|l|l|l|l|l|}
\hline & Total & Switching to PD & Switching to HD & P-value \\
\hline Age at switching & $66.9 \pm 16.8$ & $62.5 \pm 15.9$ & $68.8 \pm 16.8$ & 0.016 \\
\hline & {$[21.5-92.2]$} & {$[23.0-92.2]$} & {$[21.5-89.5]$} & 0.000 \\
\hline Time to first switch: Months & $21.3 \pm 22.9$ & $10.9 \pm 18.1$ & $25.9 \pm 23.4$ & 0.000 \\
\hline Time to first switch: Years & $1.7 \pm 1.8$ & $2.13 \pm 1.9$ & $0.9 \pm 1.5$ & 0.000 \\
\hline Tim switch category & & & & $16(11.8)$ \\
\hline$<3$ months & $47(24)$ & $31(51.7)$ & $32(23.5)$ \\
\hline $3-12$ months & $48(24.5)$ & $16(26.7)$ & $30(22.1)$ \\
\hline $12-24$ months & $35(17.9)$ & $5(8.3)$ & $58(42.6)$ & \\
\hline$\geq 24$ months & $66(33.6)$ & $8(13.3)$ & \\
\hline
\end{tabular}

patients who switched modalities compared to those who remained on their initial modality. Comparison of patients switched from PD to those switched from HD is also presented.

Comparison between HD patients switching to PD and PD patients switching to HD: The first group was significantly younger at the time of the switch. They were less likely to be treated with EPO at baseline, had higher values for serum creatinine at baseline, were more likely to start dialysis in emergency, had lower BMI, were more often treated with EPO after dialysis start, had lower haemoglobin and were less likely to have a professional activity. For the other characteristics, no significant differences had been found.

Comparison between PD patients switching to HD and PD patients remaining on their initial modality: In the first group, patients were more likely to start dialysis in emergency, less likely to have cardiovascular disease, and more likely to walk without help. The proportion of hospitalization is higher for switching patient after the initiation of the dialysis. There was no other demographic, clinic, or laboratory statistically significant difference.
Comparison between HD patients switching to PD and HD patients remaining on their initial modality: In the first group, patients were younger, less likely to be treated EPO at baseline, had lower BMI, had significantly higher level of serum creatinine at baseline, and were more likely to have started dialysis in emergency. There was no statistically significant difference in the other demographic, clinic, or laboratory data.

Time to switch from one dialysis modality to another: The time elapsed between the initial treatment and the switching to another one was $21.39 \pm 22.96$ months. The time was significantly longer for patients switching from PD to HD compare with HD to PD: $25.9 \pm 23.44$ months, $10.95 \pm 18.14$ months subsequently, $\mathrm{p}=0.000$.

In total, $48.5 \%$ of patients changed the modality of dialysis during the first year of dialysis, $17.9 \%$ during the second year, and $33.7 \%$ after 2 years of initial dialysis. Time to first modality switch was significantly different between patients switching from HD to PD and those from PD to HD, $p=0.000$ (Table 2). 
Citation: Habib A, Anne-Claire D, Sambuc R, et al. (2020) Switching between Dialysis Modality: A Descriptive Study in Provence-Alpes-Côte D'azur. Ann Nephrol 5(1):60-70

Table 3: Mortality rate for all patients at a point date.

\begin{tabular}{|l|l|l|}
\hline Comparison groups & Mortality rate $\%$ & P value $\left(\mathbf{X}^{\mathbf{2}}\right)$ \\
\hline Total start on PD versus total start on HD & 42.3 vs. 49.7 & 0.002 \\
\hline Only one switch versus non-switch & 39.3 vs. 49.6 & 0.005 \\
\hline Remained on PD versus remained on HD & 44.2 vs. 49.9 & 0.056 \\
\hline Switch to PD versus switch to HD & 38.3 vs. 39.7 & 0.875 \\
\hline Switch to PD versus remained on HD & 38.3 vs. 49.9 & 0.091 \\
\hline Switch to HD versus remained PD & 39.7 vs. 44.2 & 0.407 \\
\hline
\end{tabular}

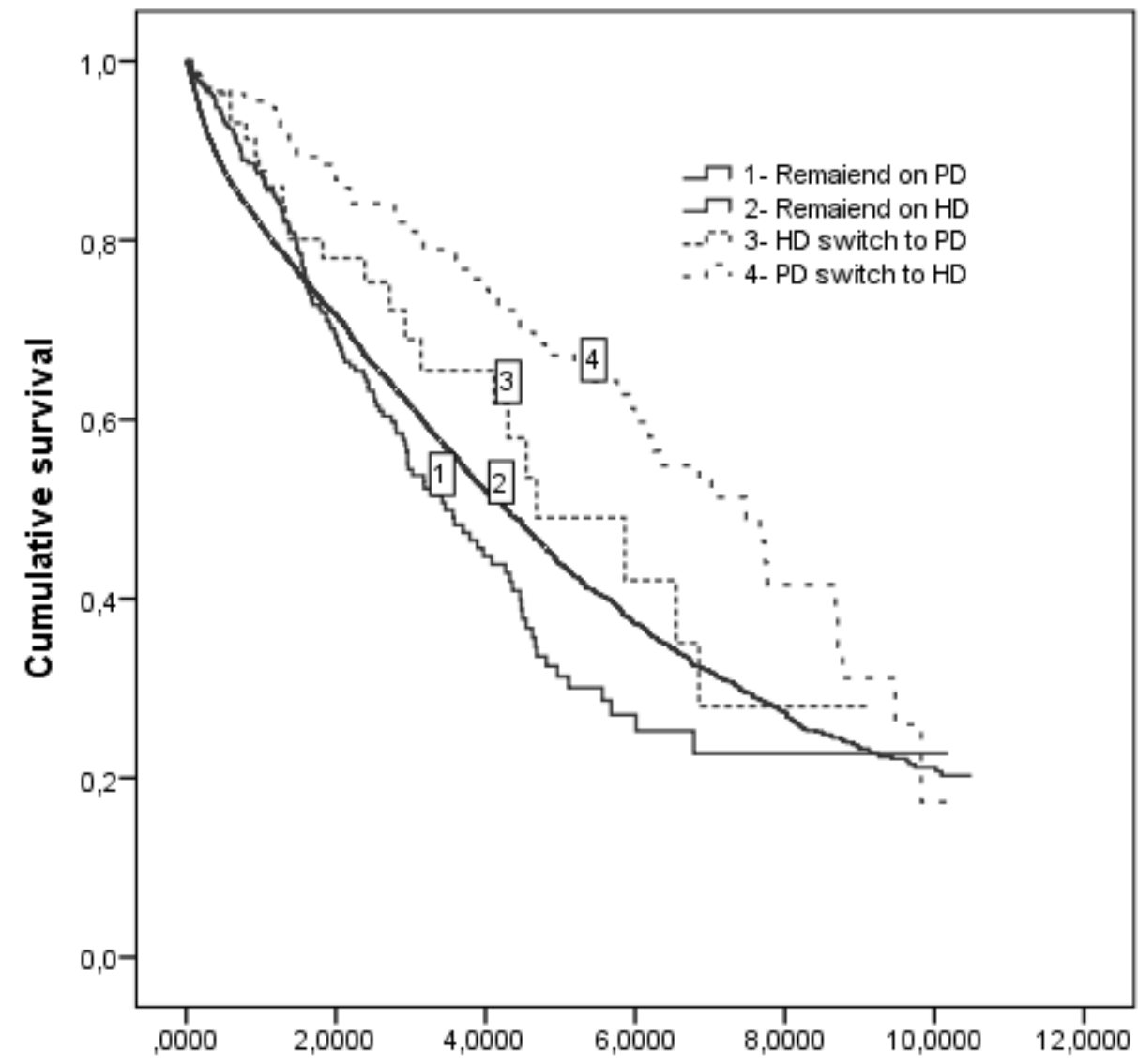

Follow-Up, Years

Figure 1: Kaplan-Meier survival curve by dialysis modality: Switched to HD, switch to PD remained on PD, remained on HD.

\section{Patient outcome}

Mortality rate: Table 3 represents mortality rate at a point date (June $30^{\text {th }} 2014$ ) for all patients.

Among the 7,203 patients, the mortality rate was $49.2 \%$ (3,547 patients). Disregarding a switch or not, the rate of DP patient is lower than HD patients as first treatment $42.3 \%$, $49.7 \%$ respectively, $p=0.002$. But the difference decreased for patients remaining in their first modality (44.2\% for PD vs. 49.9\% for HD, $p=0.056$ ).

Mortality rate was significantly lower for switching patients compared to non-switching: Respectively 77 (39.3\%) vs. $3462(49.6 \%), p=0.005$.

Relatively the same mortality rate was observed for pa- tients who switched to PD or to HD: $p=0.875$.

Transplantation: In total, $24 \%$ of switching patients have been transplanted. Renal transplantation was significantly higher in patients switching from HD to PD in comparison to those switching from PD to HD, $p=0.002$.

Survival: Median survival times on PD initial and on HD initial (start on PD or on HD) were comparable as expected: 4.28 years and 4.49 years respectively. But, median survival time for non-switching patients was higher for patients treated with HD compared to DP (Figure 1). Switching patients had higher survival chance in comparison to non-switching patients (Table 4).

Median survival time for switching patients was 6.85 years; 
Citation: Habib A, Anne-Claire D, Sambuc R, et al. (2020) Switching between Dialysis Modality: A Descriptive Study in Provence-Alpes-Côte D'azur. Ann Nephrol 5(1):60-70

Table 4: Average and median of survival time and survival rate according to dialysis modalities at start of dialysis and according dialysis modalities switch.

\begin{tabular}{|c|c|c|c|c|c|c|c|}
\hline & \multirow[b]{2}{*}{$\mathbf{N}$} & \multicolumn{2}{|l|}{ Survival } & \multicolumn{4}{|c|}{ Survival rate $\%$} \\
\hline & & $\begin{array}{l}\text { Moyne } \\
\text { [IC 95\%] }\end{array}$ & $\begin{array}{l}\text { Median } \\
\text { [IC à 95\%] }\end{array}$ & 1 ys & 2 ys & 3 ys & 4 ys \\
\hline Total & 7172 & $\begin{array}{l}5.01 \\
{[4.9-5.1]}\end{array}$ & $\begin{array}{l}4.31 \\
{[4.15-4.47]}\end{array}$ & 82.3 & 72.2 & 61.8 & 52.4 \\
\hline Switch to PD: HD $\rightarrow$ DP & 60 & $\begin{array}{l}5.2 \\
{[4.2-6.3]}\end{array}$ & $\begin{array}{l}4.7 \\
{[2.9-6.4]}\end{array}$ & 87.7 & 78 & 68.9 & - \\
\hline Switch to HD: DP $\rightarrow \mathrm{HD}$ & 136 & $\begin{array}{l}6.6 \\
{[5.9-7.3]}\end{array}$ & $\begin{array}{l}7.5 \\
{[6.1-8.8]}\end{array}$ & 95.6 & 86.7 & 82 & - \\
\hline \multicolumn{8}{|c|}{ Dialysis modality at start of dialysis } \\
\hline Start on HD & 6724 & $\begin{array}{l}4.9 \\
{[4.9-5.1]}\end{array}$ & $\begin{array}{l}4.3 \\
{[4.1-4.5]}\end{array}$ & 81.8 & 71.8 & 61.6 & 52.2 \\
\hline Start on DP & 448 & $\begin{array}{l}5.2 \\
{[4.8-5.7]}\end{array}$ & $\begin{array}{l}4.5 \\
{[3.8-5.1]}\end{array}$ & 90 & 74.9 & 64.1 & 55.7 \\
\hline Total/non-switch & 6976 & $\begin{array}{l}4.9 \\
{[4.8-5.1]}\end{array}$ & $\begin{array}{l}4.3 \\
{[4.1-4.4]}\end{array}$ & 82 & 71.6 & 61.3 & 51.8 \\
\hline Total/only one switch & 196 & $\begin{array}{l}6.3 \\
{[5.7-6.9]}\end{array}$ & $\begin{array}{l}6.8 \\
{[5.5-8.1]}\end{array}$ & 93.2 & 84.1 & 78.4 & \\
\hline \multicolumn{8}{|l|}{ Dialysis modality switch } \\
\hline Remained on HD & 6664 & $\begin{array}{l}4.9 \\
{[4.8-5.1]}\end{array}$ & $\begin{array}{l}4.3 \\
{[4.1-4.4]}\end{array}$ & 81.7 & 71.7 & 61.5 & 52 \\
\hline Remained on DP & 312 & $\begin{array}{l}3.9 \\
{[3.9-5.1]}\end{array}$ & $\begin{array}{l}3.5 \\
{[2.6-4.2]}\end{array}$ & 87.5 & 69.2 & 54.5 & 44.7 \\
\hline
\end{tabular}

7.48 years for patients who initially started on PD and were switched to $H D[D P \rightarrow H D]$ and 4.68 years for patients who initially started on HD and were switched to PD [HD $\rightarrow D P])$.

Survival rate of the switching patients was $93.2 \%$ at one year $(95.6 \%$ of the group PD $\rightarrow H D, 87.7 \%$ of $H D \rightarrow P D)$ and $84.1 \%$ at two years $(86.7 \%$ of the group $\mathrm{DP} \rightarrow \mathrm{HD}, 78 \%$ of the group HD $\rightarrow$ DP).

\section{Survival risk factors for switching patients $(n=$ 196)}

Table 5 shows the results of univariate and multivariate analysis for switching patients survival, based on each potential risk factor.

In the model 1 (c.f. Statistical analysis): Advanced age, time switch category ( $<3$ months) and the presence of diabetes disease were identified as significant factors $(p<0.05)$. In the model 2 (c.f. Statistical analysis), time switch category $(<$ 3 months), mobility (totally dependent or need assistance for transfers) were identified as significant factors.

The relative risk of death was not significantly different between the patients who switched to HD and those who switched to PD.

Among patients who started on HD, switching to PD was not identified as a survival risk factor $p=0.268$. In contrast the switching to HD improved significantly the survival for those who had started on PD: RR adjusted ${ }^{\mathrm{a}}=2.01$ [1.22-3. 61], $\mathrm{p}=$ 0.007 .

\section{Propensity score}

Kaplan-Meier survival analysis plots showed that there was no difference in the unadjusted mortality rate between propensity score-matched groups: $\mathrm{HD} \rightarrow \mathrm{PD}$ and $\mathrm{PD} \rightarrow \mathrm{HD}$ patients matched with similar propensity score: (log-rank, $p=$ 0.447 ) (Figure 2), $\mathrm{HR}=0.726 ; 95 \%$ confidence interval $(\mathrm{Cl})$, $0.37-1.54 ; p=0.761$.

\section{Discussion}

In this cohort study, we analyzed and compared the main characteristics and the outcome of the patients who switched from one dialysis modality to the other: From HD to PD or from PD to HD. Firstly, our main findings confirmed switching from HD to PD was less often than switching from PD to HD. Secondly, the duration on initial treatment before switching was longer for PD. Thirdly, the survival rate was significantly higher for switching patients comparing to non-switching. Thus, PD patients who switched to HD had higher survival chance in comparison with HD patients who switched to PD, but this difference was not significant even after matched groups with similar propensity score.

aRelative risk of patients who remained on their initial treatment PD compared to those who switched to HD. 
Citation: Habib A, Anne-Claire D, Sambuc R, et al. (2020) Switching between Dialysis Modality: A Descriptive Study in Provence-Alpes-Côte D'azur. Ann Nephrol 5(1):60-70

Table 5: Univariate and multivariate analyses for factors influencing survival among switching patients by log rank and Cox proportional hazards regression.

\begin{tabular}{|c|c|c|c|c|c|}
\hline \multirow[t]{2}{*}{$N=196$} & \multirow{2}{*}{\begin{tabular}{|l} 
Log rank \\
P \\
\end{tabular}} & \multicolumn{2}{|l|}{ Cox : Model 1} & \multicolumn{2}{|l|}{ Cox : Model 2} \\
\hline & & $\mathrm{HR}[\mathrm{IC}]$ & $P$ & $\mathrm{HR}[\mathrm{IC}]$ & $p$ \\
\hline Dialysis modality switch & 0.059 & & & & \\
\hline \multicolumn{6}{|l|}{$H D \rightarrow D P$} \\
\hline \multicolumn{6}{|l|}{$\mathrm{DP} \rightarrow \mathrm{HD}$} \\
\hline Time switch category & 0.000 & & 0.000 & & 0.000 \\
\hline$<3$ months & & $13.9[6.4-30.2]$ & 0.000 & $7.9[3.49-18.18]$ & 0.000 \\
\hline 3-12 months & & $2.2[1.1-4.8]$ & 0.045 & $1.9[0.83-4.80]$ & 1.22 \\
\hline $12-24$ months & & $3.6[1.6-8.1]$ & 0.002 & $3.7[1.05-9.02]$ & 0.004 \\
\hline$>24$ months & & 1 & & 1 & \\
\hline Sex $F$ & 0.179 & & & & \\
\hline Age category & 0.000 & & 0.001 & & \\
\hline$<45$ & & 1 & & & \\
\hline $45-65$ & & $1.1[0.3-4.1]$ & 0.91 & & \\
\hline $65-75$ & & $3.5[1.1-12.6]$ & 0.049 & & \\
\hline$\geq 75$ & & $4.2[1.3-14.1]$ & 0.019 & & \\
\hline Albumin & 0.307 & & & & \\
\hline \multicolumn{6}{|l|}{$<25$} \\
\hline \multicolumn{6}{|l|}{$25-36$} \\
\hline \multicolumn{6}{|l|}{$\geq 36$} \\
\hline Haemoglobin $<12$ vs. $\geq 12$ & 0.816 & & & & \\
\hline BMI & 0.708 & & & & \\
\hline \multicolumn{6}{|l|}{$<18.5$} \\
\hline \multicolumn{6}{|l|}{$18.5-25$} \\
\hline \multicolumn{6}{|l|}{$25-30$} \\
\hline \multicolumn{6}{|l|}{$\geq 30$} \\
\hline EPO initial & 0.693 & & & & \\
\hline Urgent & 0.455 & & & & \\
\hline Diabetes & 0.007 & $1.92[1.1-3.3]$ & 0.014 & & \\
\hline HTA & 0.330 & & & & \\
\hline Cardiovascular disease & 0.179 & & & & \\
\hline Respiratory disease & 0.062 & & & & \\
\hline KC & 0.903 & & & & \\
\hline Number co-morbidity & 0.016 & & & & \\
\hline \multicolumn{6}{|l|}{0} \\
\hline \multicolumn{6}{|l|}{1} \\
\hline \multicolumn{6}{|l|}{$\geq 2$} \\
\hline Mobility & 0.004 & & & & 0.003 \\
\hline Walk without help & & & & 1 & \\
\hline Totally dependent & & & & $3.5[1.6-7.6]$ & 0.001 \\
\hline Need assistance & & & & $2.1[0.7-5.8]$ & 0.18 \\
\hline Hospitalization & 0.542 & & & & \\
\hline Handicap & 0.020 & & & & \\
\hline Activity professional & 0.004 & & & $0.19[0.47-0.81]$ & 0.025 \\
\hline Primary renal disease & 0.243 & & & & \\
\hline
\end{tabular}



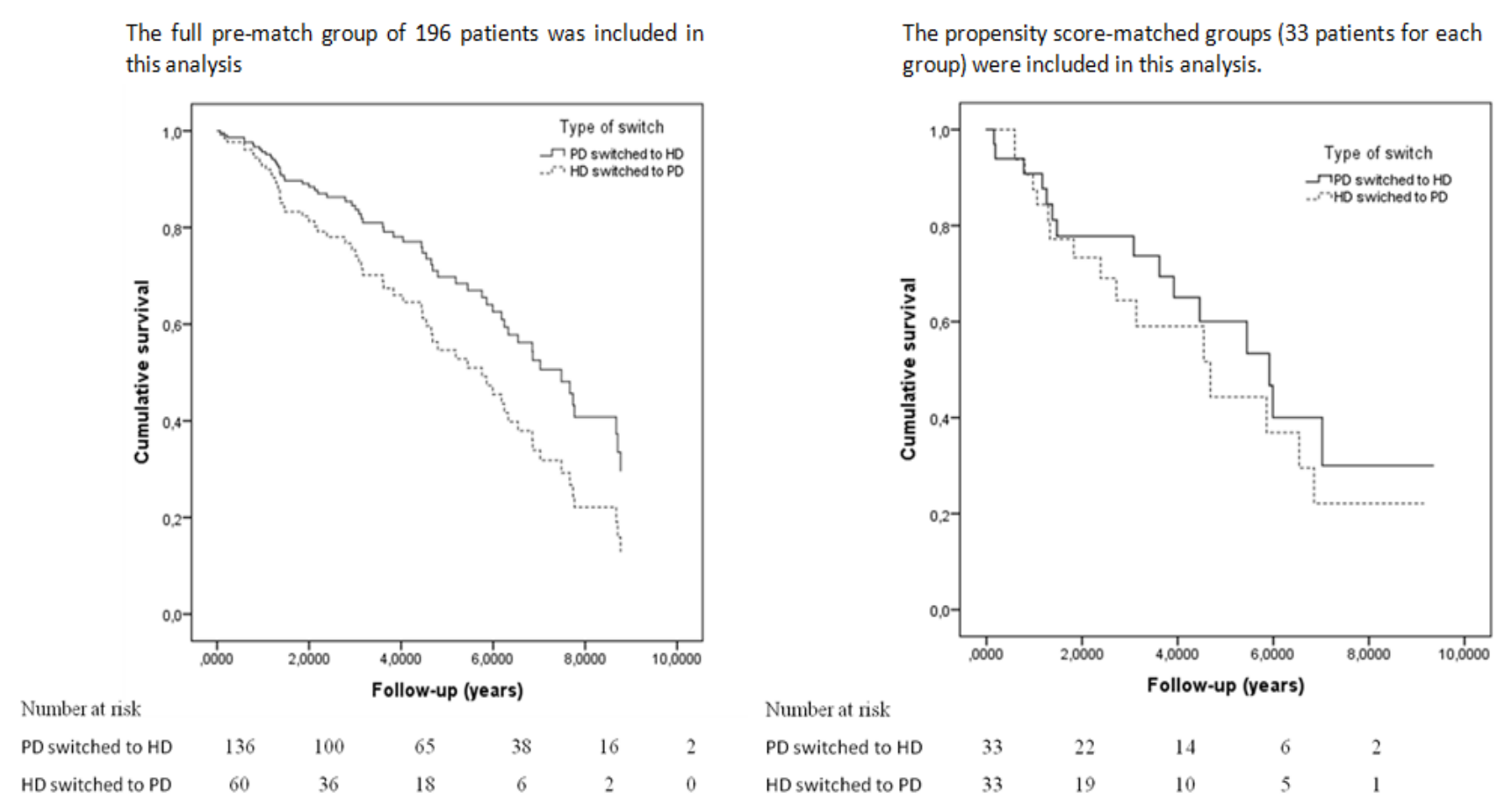

Figure 2: Kaplan-Meier survival curve by type of switch: Switched to HD, switch to PD, before and after propensity score matched.

Similarly to our results, the literature shows that HD patients switching to PD are less frequent than those switching from PD to HD $[17,20,28,40]: 4.05 \%$ versus $23.1 \%$ in the Netherland [28]; $1.7 \%$ versus $14 \%$ in Spain [17] and $5 \%$ versus $24.8 \%$ in United States [20]. According to the literature, these differences might be based on the belief that PD has particular benefits as an initial dialysis modality. Nevertheless, many patients will eventually require $\mathrm{HD}$ at medium or long term. The rational underlying is first PD is generally less costly during the early years on dialysis [41], and secondly among HD and PD patients, there is no statistically significant difference in quality of life [42]. The survival rate is better on PD compared to $H D$ at least over the first two years of dialysis treatment [43]. Nevertheless, after few years ( 2 or 3 ), the outcome of PD as first therapy becomes equal to HD, or worse [20,44].

Starting treatment with PD and then switching to HD is driven by in these other following argument: With the declining of residual renal function (RRF) with time spent on PD, the PD may become inadequate [13]. The RRF is better in PD compared to HD during the first years of dialysis. Preservation of RRF improves the overall survival rate and quality of life both in PD and HD patients. Moreover, the preservation of RRF is necessary for obtaining adequate clearance [45-47].

Vascular access can become a problematic in long term treatment of HD patients and hence starting the treatment with PD can postpone the need of creating an arteriovenous fistula [48]. So the programs for renal hemodialysis treatment should include both PD and HD modalities, due to their complementarity.

Similar to ours results, although patient starting with PD therapy were more likely to change modality at least once, patients starting HD therapy were more likely to change mo- dality within court time as confirmed by Johnson, et al. [49]. In their study, the switching rates from PD and from HD were $8.5 \%$ vs. $21.1 \%$, at 6 months, $27.9 \%$ vs. $24.7 \%$ at 2 years and $63.6 \%$ vs. $26.9 \%$ at 6 years. Jaar, et al. [35], in a prospective study of 292 PD patients, found that among the $24.8 \%$ PD who switched to HD, 40\% switched within the first year and $70 \%$ within two years. On the other side, Guo, et al. [50] found that the switching rate of patients to HD was usually higher in the first year than in subsequent years on DP.

In contrast to our study, switching to HD decreased during the follow up, from $40 \%$ during the first 3 months to $25 \%$ after 2 years, due mainly to complications [37].

In our study, the duration of the first dialysis modality before switching to another was $25.9 \pm 23.44$ months for PD patients and $10.95 \pm 18.14$ months for HD patients. In Basse-Normandie (one French region), median duration on PD was 22 months [39].

The differences in the duration of the first modality may be due to medical reasons of switching [51] or to patients characteristics. Unfortunately, in our study, we didn't analyze the reasons for switching due to the lack of available data.

The literature suggested that the main reasons for switching patient from HD to PD are vascular access problems, cardiac disease, and patient preference [30,32-34,38,48,52-54]. On the other hand, the main reasons for switching patient from PD to HD [31,34-36,39,48,52,55-61] are complications related or non-related to PD: Peritonitis, ultra-filtration problems, catheter problems, social factors or patient preferences.

In France (in Haute and Basse-Normandie), Lobbedez, et al. [38] retrospectively assessed 25 patients treated by HD be- 
tween 1992 and 2002 and subsequently switched to PD. The reasons for switching were vascular access problems (13/25), cardiovascular problems (7/25), and patient's choice (5/25). On the other hand, BOISSINOT, et al. [39] retrospectively assessed 60 patients (in Basse-Normandie) treated by PD between 2005 and 2009 and subsequently switched to HD due to technique failure. The most frequent causes for technique failure were peritonitis $(n=21)$ and dialysis inadequacy $(n=$ 13).

In our study, HD patients who switched to PD compared with those PD patients who switched to HD were significantly younger at time of switch, more likely to start dialysis in emergency, and less likely to have a professional activity. They were also less likely to be treated with EPO at baseline, had higher serum creatinine level at baseline, had lower BMI, and were more likely to be treated with EPO after the beginning of dialysis, had lower haemoglobin value, and were less likely to have a professional activity.

Regarding the age, similar results were found by Unal, et al. [52] and Biesen, et al. [34]. In our study, PD patients who switched to HD, compared with those who remained on PD, were more likely to start dialysis in emergency, less likely to have cardiovascular diseases and to walk without help. But in other studies, PD patients who switched to HD were younger, had higher serum albumin level, higher proportion of hypertension [36], higher proportion of CAD, higher proportion of diabetes [31], higher BMI value, and higher serum creatinin value [35].

In this study we compared patients who switched from HD to PD with those who remained on HD but, in the literature, most studies compared them with those who remained on PD $[30,32,54]$. According to our study, HD patients who switched to PD were younger, less likely to be treated with EPO at baseline, had lower BMI, had significantly higher serum creatinin at baseline, and were more likely to start dialysis in emergency.

The impact on outcome of switching from one dialysis modality to other remains controversial. We found no significant difference in mortality rate of PD patients who switched to HD or vice versa. But mortality rate was significantly different between switched patients compared to non-switched patients. This finding suggested that switching between dialysis modality might be a protector factor. When we compared PD and $\mathrm{HD}$ as first treatment, mortality rate was significantly higher for HD patient $(42.3 \%$ among PD and $49.7 \%$ among HD, $p=$ 0.002 ). But when we compared only HD and PD patient who remained on their initial treatment the difference in mortality rate decreased (44.2\% for PD and $49.9 \%$ for HD, $p=0.051$ ).

Similar to ours, Biesen, et al. [34] found that switching PD patient to HD is associated with an improved survival rate, whereas switching HD patient to PD is not.

In contrast to ours, switching patient from HD to PD modality had a higher risk of death versus those who remained on their initial modality $[33,38,53,62]$. However, our finding was in agreement with few studies that showed no significant differences between these groups $[30,32,54,60]$.
Similar to ours, mortality rate was lower for PD patients who switched to HD compared with those who remained on their initial modality [34,36,48,63].

These differences in outcome might be explained by differences in patient's characteristics. In ours study, the survival risk factors for switching patient were advanced age, diabetes, and time switch (the duration of the first dialysis modality before switching).

The duration on initial treatment before switch and/or the duration on new treatment after switch could improve the outcome, but they weren't enough taken into account in the literature. Furthermore, the database for duration on HD or on PD before switch was not always accessible. Only two studies have analyzed the duration on PD before switching to $\mathrm{HD}$ as risk factors $[55,63]$. However, the duration on HD before switch to PD, was not available for all literature studies and has not been analyzed as a risk factor.

In our study, the duration of PD treatment before switching to HD, less than 24 months, was a significant predictor of mortality. In contrast, Wiggins, et al. [63] found that the duration on PD before switching to HD, more than 22 months, was a significant predictor of mortality. This observation is not clear and need to be confirmed by further work.

\section{Strengths and limitations of our work}

To our knowledge, this is the first study where that analyzed the characteristics and the outcome of all the patients who switched either from HD to PD or from PD to HD in PACA region. Secondly, this analysis was multicentre. Thirdly, we included all the incident patients in PACA over the 9-years period.

Despite the strengths, this study is not without limitations: In databases, the reasons of switching between dialysis modalities were not clearly available. Moreover, we had clinical data at baseline only, so we did not measure and monitor changes concerning comorbidities or other clinical data.

In conclusion, this study confirms that the ESRD patients who started dialysis by PD were more likely to change their treatment than those who started dialysis by HD. The switching patients appeared to be more beneficial than no-switching one, in terms of improving survival rate. In fact, switching to HD may improve positively the survival compared to those who remained on PD, whereas, switching to PD was not. The time switch (duration on initial treatment before switching) was a significant factor of mortality for switching patient.

\section{Concise Methods}

\section{Study population}

Provence-Alpes-Côte d'Azur is a region of France where the "REIN" registry is providing since 2004 quality controlled data about patients treated for ESRD.

All new patients who began dialysis therapy in region PACA between 2004 and 2012, and their trajectories since 
the first dialysis modality until 30/06/2014, were viewed retrospectively. Switching from a dialysis modality to another was defined as patients who were initially treated by PD and subsequently switched to HD or vice versa. Patients younger than 18, were excluded from the study. We identified 7206 subjects aged over 18 . To avoid complex interpretations, patients who switched twice or more between dialysis modalities were not included (31 patients).

\section{Data source}

The data used for this study were issued from the REIN (Renal Epidemiology and Information Network) registry data. The REIN registry has been described in detail by Couchoud, et al. [64].

Data gathered for this study included patient demographics (age, sex), clinical data of pre-dialysis period, erythropoietin-stimulating agents (EPO), initial value of creatinine $(\mu \mathrm{mol} / \mathrm{l})$, serum albumin $(\mathrm{g} / \mathrm{l})$ and haemoglobin $(\mathrm{g} / \mathrm{l})$. Clinics after start of dialysis were body mass index, albumin $(\mathrm{g} / \mathrm{l})$, haemoglobin $(\mathrm{g} / \mathrm{l})$, erythropoietin-stimulating agents (EPO), and starting dialysis for end-stage renal disease in emergency units. Primary renal diseases before dialysis were included. The co-morbidities assessed were diabetes disease, chronic respiratory disease (respiratory failure with and without oxygen therapy), cardiovascular disease (coronary artery disease, rhythm disorder, heart failure, peripheral vascular disease, abdominal aortic aneurysm, cerebrovascular accident, transient ischemic attack). The hypertension was considered as risk factors and not as comorbidity. The Number of co-morbidities was assessed by the 12 comorbidities: Diabetes, respiratory failure, cerebrovascular accident, abdominal aortic aneurysm, peripheral arterial disease, arrhythmia, cancer, and liver disease, heart failure, coronary artery disease, (HIVAIDS) and transplant.

Handicaps were classified as presence of handicap or not (yes/no). Mobility was classified into three groups according to patient dependence. Body mass index (BMI) was calculated as weight $(\mathrm{kg}) / \mathrm{square}$ root of height $(\mathrm{m})$. The professional activity of the patient was classified as yes/no response as well as the hospitalization period.

Time to first modality switch was given by the interval between the time of dialysis initiation and the time of the first switch. The outcomes taken into account were survival, death and renal transplantation.

\section{Statistical analysis}

Continuous variables were expressed as means and standard deviations. Categorical variables were expressed as number of subjects and proportion. Categorical variables were compared using the $\chi^{2}$ test, and continuous variables were compared using the T-test.

Analysis of survival was done by Cox regression method (step by step) and by Kaplan-Meier method with comparison of groups by the log rank test. Patients were censored at transplantation, loss of sight and the end of the study period (30/03/2014).

For the Cox regression method, we used two models; the first model (model 1) included: Sex, age, emergency, diabetes, time switch category, chronic respiratory disease, number of co-morbidities, cardiovascular disease and type of switch. The second model (model 2) included: Sex, age, emergency, diabetes, time switch category, chronic respiratory disease, number of co-morbidities, cardiovascular disease, type of switch, handicap and mobility.

Statistical analysis was conducted using SPSS program. A $p$-value $<0.05$ was defined as statistically significant.

\section{Acknowledgments}

We thank all registry participants, especially the nephrologists and the professionals who collected the data and conducted the quality control.

\section{Statement of Competing Financial Interests}

We declare that we have no competing interests.

\section{References}

1. Agarwal M, Clinard P, Burkart JM (2003) Combined peritoneal dialysis and hemodialysis: Our experience compared to others. Perit Dial Int 23: 157-161.

2. Suzuki H, Hoshi $H$, Inoue T, et al. (2012) New modality of dialysis therapy: Peritoneal dialysis first and transition to home hemodialysis. Adv Perit Dial 28: 106-111.

3. Couchoud C, Savoye E, Frimat L, et al. (2008) Variability in case mix and peritoneal dialysis selection in fifty-nine French districts. Perit Dial Int 28: 509-517.

4. Du Halgouet C, Azeroual L, Verhoeven AS, et al. (2012) Facteurs médicaux et non médicaux limitant le développement de la dialyse péritonéale: Analyse d'un programme d'information prédialyse. Néphrologie \& Thérapeutique 8: 322.

5. Durand PY, Rusterholz T, Supreme Healthcare Authority of France (2009) French 2008 guidelines on peritoneal dialysis: Indications and non-indications. Néphrologie \& Thérapeutique 4: S281-S285.

6. Grenêche S, D'Andon A, Jacquelinet C, et al. (2005) Choosing between peritoneal dialysis and haemodialysis: A critical appraisal of the literature. Néphrologie \& Thérapeutique 1: 213-220.

7. Holley JL, Barrington K, Kohn J, et al. (1991) Patient factors and the influence of nephrologists, social workers, and nurses on patient decisions to choose continuous peritoneal dialysis. Adv Perit Dial 7: 108-110.

8. Just PM, de Charro FT, Tschosik EA, et al. (2008) Reimbursement and economic factors influencing dialysis modality choice around the world. Nephrol Dial Transplant 23: 2365-2373.

9. Lebrun G, Lowe $Y$, Jaubert D, et al. (2012) Facteurs influençant le choix de la technique chez les patients incidents en dialyse en 2011. Néphrologie \& Thérapeutique 8: 407.

10. Mahajan S, Tiwari SC, Kalra V, et al. (2004) Factors affecting the use of peritoneal dialysis among the ESRD population in India: A single-center study. Perit Dial Int 24: 538-541.

11. Nissenson AR, Prichard SS, Cheng IK, et al. (1993) Non-medical factors that impact on ESRD modality selection. Kidney Int Suppl 40: S120-S127.

12. Wauters JP, Uehlinger D (2004) Non-medical factors influencing peritoneal dialysis utilization: The Swiss experience. Nephrol Dial Transplant 19: 1363-1367. 
13. Covic A, Bammens B, Lobbedez T, et al. (2010) Educating endstage renal disease patients on dialysis modality selection. NDT Plus 3: 225-233.

14. (2013) Rapport annuel 2013. REIN, Agence de la biomédecine.

15. Chaudhary K, Sangha H, Khanna R (2011) Peritoneal dialysis first: Rationale. Clin J Am Soc Nephrol 6: 447-456.

16. Chaudhary K (2011) Peritoneal dialysis drop-out: Causes and prevention strategies. Int J Nephrol 2011: 434608.

17. Rufino JM, García C, Vega N, et al. (2011) Current peritoneal dialysis compared with hemodialysis: Medium-term survival analysis of incident dialysis patients in the Canary Islands in recent years. Nefrologia 31: 174-184.

18. Mircescu G, Garneata L, Florea L, et al. (2006) The success story of peritoneal dialysis in Romania: Analysis of differences in mortality by dialysis modality and influence of risk factors in a national cohort. Perit Dial Int 26: 266-275.

19. Nordio M, Limido A, Maggiore U, et al. (2012) Survival in patients treated by long-term dialysis compared with the general population. Am J Kidney Dis 59: 819-828.

20. Jaar BG, Coresh J, Plantinga LC, et al. (2005) Comparing the risk for death with peritoneal dialysis and hemodialysis in a national cohort of patients with chronic kidney disease. Ann Intern Med 143: 174-183.

21. Perl J, Wald R, McFarlane P, et al. (2011) Hemodialysis vascular access modifies the association between dialysis modality and survival. J Am Soc Nephrol 22: 1113-1121.

22. Yeates $\mathrm{K}$, Zhu N, Vonesh E, et al. (2012) Hemodialysis and peritoneal dialysis are associated with similar outcomes for end-stage renal disease treatment in Canada. Nephrol Dial Transplant 27: 3568-3575.

23. Mehrotra R, Chiu YW, Kalantar-Zadeh K, et al. (2011) Similar outcomes with hemodialysis and peritoneal dialysis in patients with end-stage renal disease. Arch Intern Med 171: 110-118.

24. Sanabria M, Muñoz J, Trillos C, et al. (2008) Dialysis outcomes in Colombia (DOC) study: A comparison of patient survival on peritoneal dialysis vs hemodialysis in Colombia. Kidney Int Suppl 108: S165-S172.

25. Tse KC, Lui SL, Lo WK (2003) Comparison of long-term survival (beyond 12 years) in patients on peritoneal dialysis and on hemodialysis. Perit Dial Int 2: S104-S108.

26. Maier A, Stocks F, Pommer W, et al. (2009) Hemodialysis versus peritoneal dialysis: A case control study of survival in patients with chronic kidney disease stage 5. Ther Apher Dial 13: 199-204.

27. Stack AG, Molony DA, Rahman NS, et al. (2003) Impact of dialysis modality on survival of new ESRD patients with congestive heart failure in the United States. Kidney Int 64: 1071-1079.

28. Termorshuizen F, Korevaar JC, Dekker FW, et al. (2003) Hemodialysis and peritoneal dialysis: Comparison of adjusted mortality rates according to the duration of dialysis: Analysis of The Netherlands Cooperative Study on the adequacy of dialysis 2. J Am Soc Nephrol 14: 2851-2860.

29. Heaf JG, Løkkegaard H, Madsen M (2002) Initial survival advantage of peritoneal dialysis relative to hemodialysis. Nephrol Dial Transplant 17: 112-117.

30. Najafi I, Hosseini M, Atabac S, et al. (2012) Patient outcome in primary peritoneal dialysis patients versus those transferred from hemodialysis and transplantation. Int Urol Nephrol 44: 1237-1242.
31. Kim GC, Vonesh EF, Korbet SM (2002) The effect of technique failure on outcome in black patients on continuous ambulatory peritoneal dialysis. Perit Dial Int 22: 53-59.

32. Zhang L, Cao T, Li ZB, et al. (2012) Clinical outcomes of peritoneal dialysis patients transferred from hemodialysis: A matched case-control study. Perit Dial Int 33: 259-266.

33. Zhang X, Han F, He Q, et al. (2008) Outcomes and risk factors for mortality after transfer from hemodialysis to peritoneal dialysis in uremic patients. Perit Dial Int 28: 313-314.

34. Van Biesen W, Vanholder RC, Veys N, et al. (2000) An evaluation of an integrative care approach for end-stage renal disease patients. J Am Soc Nephrol 11: 116-125.

35. Jaar BG, Plantinga LC, Crews DC, et al. (2009) Timing, causes, predictors and prognosis of switching from peritoneal dialysis to hemodialysis: A prospective study. BMC Nephrol 10: 3.

36. Panagoutsos S, Kantartzi K, Passadakis P, et al. (2006) Timely transfer of peritoneal dialysis patients to hemodialysis improves survival rates. Clin Nephrol 65: 43-47.

37. Kolesnyk I, Dekker FW, Boeschoten EW, et al. (2010) Time-dependent reasons for peritoneal dialysis technique failure and mortality. Perit Dial Int 30: 170-177.

38. Lobbedez T, Crand A, Le Roy F, et al. (2003) Transfer from chronic haemodialysis to peritoneal dialysis. Néphrologie \& Thérapeutique 1: 38-43.

39. Boissinot L, Landru I, Cardineau E, et al. (2013) Is transition between peritoneal dialysis and hemodialysis really a gradual process? Perit Dial Int 33: 391-397.

40. Johnson DW, Dent H, Hawley CM, et al. (2009) Association of dialysis modality and cardiovascular mortality in incident dialysis patients. Clin J Am Soc Nephrol 4: 1620-1628.

41. Karopadi AN, Mason G, Rettore E, et al. (2013) Cost of peritoneal dialysis and hemodialysis across the world. Nephrol Dial Transplant 28: 2553-2569.

42. Liem YS, Bosch JL, Hunink MGM (2008) Preference-based quality of life of patients on renal replacement therapy: A systematic review and meta-analysis. Value Health 11: 733-741.

43. Sinnakirouchenan R, Holley JL (2011) Peritoneal dialysis versus hemodialysis: Risks, benefits, and access issues. Adv Chronic Kidney Dis 18: 428-432.

44. Ganesh SK, Hulbert-Shearon T, Port FK, et al. (2003) Mortality differences by dialysis modality among incident ESRD patients with and without coronary artery disease. J Am Soc Nephrol 14: 415-424.

45. Kjaergaard KD, Jensen JD, Peters CD, et al. (2011) Preserving residual renal function in dialysis patients: An update on evidence to assist clinical decision making. NDT Plus 4: 225-230.

46. Rroji M, Seferi S, Cafka M, et al. (2013) Is residual renal function and better phosphate control in peritoneal dialysis an answer for the lower prevalence of valve calcification compared to hemodialysis patients? Int Urol Nephrol 46: 175-182.

47. Ryckelynck JP, Goffin É, Verger C, et al. (2013) Maintaining residual renal function in patients on dialysis. Néphrologie \& Thérapeutique 9: 403-407.

48. Van Biesen W, Dequidt C, Vijt D, et al. (1998) Analysis of the reasons for transfers between hemodialysis and peritoneal dialysis and their effect on survivals. Adv Perit Dial 14: 90-94. 
49. Johnson DW, Dent H, Hawley CM, et al. (2009) Associations of dialysis modality and infectious mortality in incident dialysis patients in Australia and New Zealand. Am J Kidney Dis 53: 290277.

50. Guo A, Mujais S (2003) Patient and technique survival on peritoneal dialysis in the United States: Evaluation in large incident cohorts. Kidney Int Suppl 88: S3-S12.

51. (2014) Sorties.

52. Unal A, Kocyigit I, Sipahioglu MH, et al. (2011) Comparison and causes of transfer from one dialysis modality to another. Int Urol Nephrol 43: 513-518.

53. Koc $Y$, Unsal A, Basturk T, et al. (2012) Is there impact of mortality prior hemodialysis therapy in peritoneal dialysis patients? Nefrologia 32: 335-342.

54. Liberek T, Renke M, Skonieczny B, et al. (2009) Therapy outcome in peritoneal dialysis patients transferred from hemodialysis. Nephrol Dial Transplant 24: 2889-2894.

55. Szeto CC, Kwan BCH, Chow KM, et al. (2010) Outcome of hemodialysis patients who had failed peritoneal dialysis. Nephron Clin Pract 116: 300-306.

56. Piraino B, Wyman AE, Sheth $H$ (2012) Examination of survival after transfer from peritoneal dialysis to hemodialysis. Adv Perit Dial 28: 64-67.

57. Bilgic A, Sezer S, Ozdemir FN, et al. (2006) Clinical outcome after transfer from peritoneal dialysis to hemodialysis. Adv Perit Dial 22: 94-98.
58. Koc Y, Unsal A, Ahbap E, et al. (2011) Clinical outcome of diabetic peritoneal dialysis patients and evaluation of factors affecting mortality: A single centre's experience from Turkey. J Ren Care 37: 94-100.

59. Chung SH, Heimbürger O, Lindholm B, et al. (2005) Peritoneal dialysis patient survival: A comparison between a Swedish and a Korean centre. Nephrol Dial Transplant 20: 1207-1213.

60. Mujais S, Story K (2006) Patient and technique survival on peritoneal dialysis in patients with failed renal allograft: A case-control study. Kidney Int Suppl 103: S133-S137.

61. Lobbedez T, Verger C, Ryckelynck JP, et al. (2012) Is assisted peritoneal dialysis associated with technique survival when competing events are considered? Clin J Am Soc Nephrol 7: 612-618.

62. Karkar A, Abdelrahman M (2011) Outcome of patients treated with automated peritoneal dialysis: Effects of selection of patients. Saudi J Kidney Dis Transplant 22: 40-48.

63. Wiggins KJ, McDonald SP, Brown FG, et al. (2007) High membrane transport status on peritoneal dialysis is not associated with reduced survival following transfer to hemodialysis. Nephrol Dial Transplant 22: 3005-3012.

64. Couchoud C, Stengel B, Landais P, et al. (2006) The renal epidemiology and information network (REIN): A new registry for end-stage renal disease in France. Nephrol Dial Transplant 21: 411-418. 